\title{
A EDUCAÇÃO DE JOVENS E ADULTOS: O COTIDIANO DA ESCOLA E AS ORIENTAÇÕES EM FORMA DE LEI
}

\author{
Cláudio Roberto Brocanelli, Mariane dos Santos Gomes \\ Universidade Estadual Paulista - UNESP, Faculdade de Filosofia e Ciências, Marília, SP. E-mail: \\ claudiobrocanelli@gmail.com.PIBID.
}

\section{RESUMO}

Este texto pretende investir numa ação interdisciplinar de formação de educadores de nossos cursos de Licenciatura de forma que estes atuem em uma realidade diferenciada de formação de pessoas em processo de Alfabetismo e Educação Básica fora da 'Idade Certa', acompanhando a Educação de jovens e Adultos. A formação de educadores de jovens e adultos busca oferecer aos sujeitos excluídos do processo de escolarização o acesso à leitura e à escrita, bem como investigar procedimentos metodológicos adequados a esse público. $O$ analfabetismo é uma problemática que envolve concepções de mundo, de homem e de sociedade, impondo-se a busca de compreensão das relações entre cultura primeira e cultura erudita, o que traz consequências para a organização dos programas de ensino. Desse modo, é necessária uma efetiva proposta de educação de jovens e adultos que avance na formação complementar nas diversas áreas do conhecimento, consolidando a prerrogativa de escolarização básica como direito público subjetivo. Ressaltem-se também as implicações da agenda internacional de educação para todos ao longo da vida. Este texto traz um estudo a partir da realidade a fim de propor reflexões sobre o tema EJA e motivar o empenho na docência.

Palavras-chave: Educação; Ensino; Gestão Escolar; EJA.

\section{THE YOUTH AND ADULT EDUCATION: SCHOOL'S DAILY LIFE AND THE GUIDANCE IN LAW FORM}

\begin{abstract}
This paper intends to invest in interdisciplinary action training educators of our education program so that they act in a different reality of training people in the process of Literacy and Basic Education outside the 'Right Age', following the Youth and Adult Education. The formation of youth and adult educators seeks to offer the excluded subject of the educational process access to reading and writing as well as investigate methodological procedures appropriate to the public. Illiteracy is a problem that involves conceptions of the world, man and society, imposing the search for understanding the relationship between first culture and erudite culture, which has consequences for the organization of educational programs. Thus, it is necessary an effective proposal for youth and adult education that advances in further training in various areas of knowledge, consolidating basic schooling prerogative as subjective public right. They also underscore the implications of the international agenda of education for all throughout life. This paper presents a study from the reality in order to propose reflections on the theme EJA and motivate the commitment to teaching.
\end{abstract}

Keywords: Education; School management; EJA. 
O Programa Institucional de Bolsas de Iniciação à Docência - PIBID, privilegia ações que motivem, ensinem e organizem a vida de nossos estudantes de forma que tenham maior e melhor engajamento na realidade escolar na atualidade; no caso do PIBID Interdisciplinar EJA, este se ocupa especificamente da Educação de Jovens e Adultos em duas escolas na cidade de Marília-SP. A partir de estudos e discussões sobre o tema, este texto pensa a própria realidade do PIBID, das escolas atendidas, de seus alunos e da própria condição educacional e a legislação que norteia o acesso à escola, bem como a permanência no ensino e as possibilidades e novas oportunidades a pessoas marginalizadas da sociedade; a principal oportunidade dessas pessoas na fase madura (jovens, adultos e idosos) é primordialmente recuperar o que, de certa forma, foi perdido por algum motivo particular ou por exclusão social e falta de acesso na chamada 'idade certa'.

O PIBID tem sido um espaço em que nossos alunos, em grande medida, trabalham de forma cooperativa, favorecendo sua própria atuação como docentes iniciantes e, principalmente, dando voz aos que frequentam estas escolas. O espaço organizado em conjunto torna-se uma espécie de laboratório, movimentando um espírito de sensibilidade com o outro e para pensar a sala de aula como lugar propício e participativo para a aprendizagem coerente com a realidade. Damos destaque ao acompanhamento em sala de aula, com os alunos, pois é espaço em que há maior proximidade e afeto, medindo as carências que invadiram as vidas excluídas socialmente.

Nas atividades desenvolvidas em conjunto, há garantia maior de envolvimento e relação do Ensino Superior com a Educação Básica, favorecendo a aproximação, articulação e revezamento entre teoria e prática, desmentindo o discurso que alimenta seu distanciamento. Para nós é impossível separar estas dimensões, a não ser que seja para entender melhor seu funcionamento; do contrário, elas estão sempre juntas, uma dando força, sabor e luz à outra. Assim, é possível um espaço de maior humanização quando desvelamos uma educação que oferece práticas reais e labor condizente com a realidade dos estudantes na forma de partilha de conhecimentos, em lugar de máquinas que vomitam conhecimentos distantes do real. Há, em vários momentos, organização nova e dinâmica diferente, justamente por promover a participação de todos, educadores e pessoas em fase de aprendizado sobre alguns conteúdos específicos.

Há a preocupação de o que pode ser feito ou não dentro da escola, no que se refere ao ensino, à sua administração e gestão. A escola pode ser considerada um lugar de formação, esta sendo o objetivo principal e o ideal que orienta o pensamento dos professores e demais envolvidos com a sua realidade. Vale ressaltar que ela é também um recurso estratégico do governo que serve justamente para governar e gerenciar ou orientar a vida das pessoas ali formadas a fim de uma adequação à sociedade, um sistema bem definido e obrigado à sua 
manutenção, ou seja, camadas e classes dominantes e dominadas, sustentando formas de vida administrada. Este ambiente pode ser, assim considerando, um controle e direcionamento da vida das pessoas. Em lugar de formação reflexiva e crítica, uma acomodação e satisfação com o que está vigente, sendo única possibilidade de vida, impossibilitando sugestões de outras formas de vida.

Com isso, reforça-se um modelo empresarial no ambiente escolar como forma de dar conta de todas as suas demandas, como se fosse uma fábrica onde se confecciona produtos, peças e coisas bem definidas em todos os seus aspectos, encaixando-se perfeitamente em um seguimento específico; este formato é gerido, desse modo, por paradigmas determinados. No entanto, a escola 'lida' com pessoas, todas inseridas em contextos históricos variados, com problemas, intenções e escolhas bem específicas ou indecisas, evolvidas em sua atualidade com novas formas possíveis que exigem também novas escolhas que podem ser claramente direcionadas processualmente, não podendo ser burocratizadas.

Uma escola com a gestão democrática efetiva é uma saída para que as relações dentro do ambiente escolar sejam pautadas na tentativa constante de formação humana que não atenda de imediato e somente a um sistema que privilegia a coisa, o produto, a compra, o consumo e qualquer modelo que aniquile a liberdade de a pessoa pensar por conta própria ou de, ao menos, expor o que pensa, quer, deseja, ama, busca, etc, com a finalidade de ser humano antes de estar imerso na selvageria do capitalismo em nossa atualidade. O modelo escolar e as intenções dos envolvidos nela deveriam estar imunes a qualquer tipo de corrupção presente na estrutura social.

Pensar seriamente quais são as especificidades da escola é fundamental para a criação de um ambiente que favoreça a formação humana de forma integral. Fazer a leitura e reflexão permanente de nossas práticas escolares de modo livre. É preciso pensar as condições e desafios ou limites a fim de que as relações diretor e professor, professor e aluno, aluno e aluno, equipe gestora e problemas cotidianos, demais pessoas, etc, sejam definidos e resolvidos não somente a partir daquilo que o sistema determina, mas que a realidade seja a própria luz para a solução de muitos desafios que se apresentam.

A conciliação entre aquilo que se apresenta nas teorias e o cotidiano escolar é um dos desafios atuais. Solução de problemas não acontece somente por meio do modelo empresarial, quando o objeto é uma escola e a própria educação objetivada no seu ambiente. Assim, seria por meio do enfrentamento do próprio ambiente que poderia buscar soluções, ou seja, indicar saídas com base em sua realidade. O que faço desse ambiente, o que faço de mim mesmo, como acontece o 'cuidado de si' e dos outros como forma de transformar a realidade da escola por ela 
mesmo... é fundamental que todos os envolvidos, professores, gestores, pais e estudantes tenham consciência do papel da escola. Porém, além do papel da escola, é preciso disposições de todos estes envolvidos também. Não basta disponibilidade de ir para a escola, mas uma disposição que alimente o desejo de todos nesse ambiente. O querer ir para a escola, o que ali trabalha ou estuda, é fonte de mudança do espaço. Assim, aquilo que se refere à burocracia, ao gerenciamento e à administração acontece em acréscimo, sendo uma consequência do trabalho desenvolvido.

A formação do professor deveria ser comparada e cumprida de acordo com outras profissões (como o médico) no que diz respeito à dedicação desde o início, inserido nos momentos de cuidado do seu 'paciente'. Cuidar da saúde humana ou da cultura humana deveria ser algo explicitamente equiparado, de igual importância. Assim como toda a equipe em um hospital prepara o ambiente para que o cirurgião tenha sucesso no momento de cuidar do corpo do paciente, também o professor deveria ter todo o ambiente preparado a fim de que seu 'paciente' saia bem depois de um dia de atividades dos cuidados da cultura. Considerando esta cena, toda a equipe gestora deveria estar a serviço do professor, o cirurgião da alma humana. Ter criteriosamente escolhidos os funcionários da escola a fim de que todo o preparo seja bem organizado a fim de o sucesso de cada ação aconteça por consequência. A escola não funciona como máquina, considerando esta como algo que funciona em sua perfeição e concatenação das engrenagens. O trabalho de educação na escola, justamente por lidar com pessoas, seja os que administram e ensinam como os que ali são instruídas, é complexo e lança desafios a cada dia. Somente seu cotidiano, à luz de teorias bem direcionadas, pode subsidiar as tomadas de decisão.

$\mathrm{Na}$ escola, todos os envolvidos com a educação, especialmente professores e direções de escola, os educadores de modo geral, devem despender todos os esforços para que o valor educacional, cultural e formativo seja reconhecido e ocupe maior espaço na preocupação com a sua vida; quando falamos de vida, esta é integral, ou seja, sugere todos os momentos vitais, incluindo a cultura como algo que devolve ou dá mais vida a cada humano, melhorando processualmente, ainda que lentamente, a própria vida. O grande problema atual é que desvinculamos os processos de educação formal dos demais momentos da vida, como se aquele não fosse parte integrante ou como se fosse uma parte, legitimando a compartimentação de toda a vida como se fosse possível viver momentos, não vivendo a vida em si.

Desejamos aqui explorar alguns pontos importantes das leis que orientam a educação no Brasil, especificamente no campo da Educação Básica, sua organização e financiamentos, bem como atuação do governo a fim de que ela se cumpra de forma progressiva. A incumbência de 
elaborar o Plano Nacional de Educação (PNE) que é uma lei prevista na LDB, na qual estabelece diretrizes, metas e estratégias para se realizar no campo da educação, é da União; isso acontece em regime de colaboração com os Estados, Distrito Federal e Municípios. Esta afirmação está contida no artigo 9 da LDB em seu inciso I. Dessa forma, os encargos são divididos entre eles sob a coordenação da União. Pode se observar que é possível uma ambiguidade na escrita do inciso, na qual deixa em aberto a responsabilidade, não dando uma função obrigatória a cada uma das partes.

É fundamental ter leis e diretrizes que orientem de forma geral a educação no país. No Brasil, a LDB tem sido a parte da legislação que dá maior suporte para que a educação receba tais orientações, bem como orientações contidas na Constituição Federal de 88 que, por sua vez, dá bases para a própria LDB. Porém, somente sob a orientação da LDB não se tem promovido a qualidade da educação da forma como ela foi concebida na época de sua elaboração. Assim, é necessário implementar outros mecanismos e estratégias de governo para que a educação se cumpra de forma quanti-qualitativa, especialmente na Educação Básica. Para que isso aconteça, já estando previsto na LDB, artigo 9, inciso l, o governo busca respaldo dos Estados, Distrito Federal e Municípios por meio do Plano Nacional de Educação, fortalecendo, de certa forma, os anseios educacionais, prevendo metas e possíveis mudanças a fim de que a legislação seja efetivada.

O financiamento da Educação Básica e, posteriormente, o FUNDEF (Fundo de Manutenção e Desenvolvimento do Ensino Fundamental e Valorização do Magistério, foi fundado pela Emenda no 14 que modificou o Art. 60 do ADCT) tem como sua base legal a constituição federal de 1988, mais especificamente no Artigo 212 e 213.

O fundamento principal contido na lei estabelece a relação entre o financiamento e a educação, previsto na Constituição Federal de 1988 onde no artigo 212 diz: A União aplicará, anualmente, nunca menos de dezoito, e os Estados, o Distrito Federal e os Municípios vinte e cinco por cento, no mínimo, da receita resultante de impostos, compreendida a proveniente de transferências, na manutenção e desenvolvimento do ensino.

Com relação ao Artigo 60 do $\mathrm{ADCT}$, este afirma que "nos dez primeiros anos da promulgação da Constituição, o Poder Público desenvolverá esforços, com a mobilização de todos os setores organizados da sociedade e com a aplicação de, pelo menos, cinquenta por cento dos recursos" a que se refere o art. 212 da Constituição, para eliminar o analfabetismo e universalizar o ensino fundamental.

$\mathrm{O}$ artigo acima foi modificado pela emenda 14 , pois ainda não havia sido colocada em prática a legislação; foram utilizados somente $15 \%$ dos $25 \%$ aprovados em lei (vindos da união 
para estados e municípios) para o Ensino Fundamental . Dessa forma, a União, que detém a maior quantidade de verbas, não se comprometeu com o financiamento educacional de fundos. $\mathrm{O}$ artigo 60, então, foi redigido da seguinte maneira: Até o 14 (décimo quarto) ano a partir da promulgação desta Emenda Constitucional, os Estados, o Distrito Federal e os Municípios destinarão parte dos recursos a que se refere o caput do art. 212 da Constituição Federal à manutenção e desenvolvimento da educação básica e à remuneração condigna dos trabalhadores da educação, respeitadas as seguintes disposições: (Redação dada pela Emenda Constitucional no 53, de 2006). (Vide Medida Provisória no 339, de 2006).

Para tais modificações o fundamento principal se faz presente na Constituição e 213 dessa Lei, em que constituição Federal determina que a União distribua, anualmente, no mínimo 18\% de sua receita.

Tendo por base autores como José Marcelino de Rezende Pinto ou Nicholas Davies e até mesmo as discussões nas aulas do assunto abordado sobre o FUNDEB, percebe-se que este não consegue garantir um financiamento adequado para a Educação Básica, pois para se conseguir um financiamento adequado deve-se levar em consideração que as escolas e o ensino devem ter um padrão mínimo de qualidade; mesmo que o FUNDEB mostre um avanço em relação ao FUNDEF, mantém-se ainda uma baixa contribuição da União no financiamento da educação Básica, pois menos de $10 \%$ é utilizado para isso. Ainda que tais financiamentos estejam reduzindo algumas desigualdades entre Estados e Municípios em relação ao recurso de educação, não é o suficiente, pois não garante que o valor-aluno mínimo anual seja atingido para todos os estados e municípios e que recursos adicionais, para além desse valor, não são especificados por Lei. É importante lembrar que a instituição de ensino deve se adequar ao valor estimado para os fins estabelecidos pelo MEC e o ministério da fazenda (em conjunto); além disso, essa verba é repassada também para instituições privadas. Há, ainda, algumas contradições dos fundos com o PNE. Pode-se afirmar, por exemplo, o desvio de verba, em que o dinheiro que seria destinado a propostas futuras é desviado, e utilizado para outros fins, ou então as práticas irregulares para contabilização de gastos, ou seja, dizer que a verba é investida em uma modalidade de ensino, sendo que, na realidade, destina-se a outra. Ou ocorre até mesmo a manipulação da declaração de dados.

Portanto, apesar de o FUNDEB ser uma proposta de melhoria do FUNDEF, abrangendo toda a educação Básica, não se pode afirmar que tal programa garanta com total convicção o financiamento adequado, pois ainda falta deixar claras as funções de cada setor (União, Estados, Distrito Federal e Municípios) a fim de buscar a adequação necessária para a realização concreta daquilo que está previsto na lei.Federal de 1988 onde se pode fazer relação com o artigo 212 
Como parte específica deste texto, destaca-se a Educação de Jovens e Adultos, sendo uma demanda importante na atualidade, pois o Brasil, de modo geral e seguindo orientações do BM, tem investido na educação para todos, de forma que também as pessoas que não tiveram a oportunidade de estarem na escola na 'idade certa' possam, agora, realizar este feito, também atendendo às exigências de governo, ou seja, a erradicação do analfabetismo, previsto no PNE, em uma de suas metas, até 2020 , lembrando que existe também, juntamente com a meta de erradicação do analfabetismo a proposta de elevar a taxa de alfabetização de pessoas com 15 anos ou mais até 2015; assim, a erradicação do analfabetismo até 2020 é dependente da proposta de melhoria do alfabetismo, comprometendo a EJA de forma que assuma tal responsabilidade em relação ao cumprimento desta meta, ainda que não tenha recursos para isso, o que prejudica, mais uma vez a efetivação das políticas públicas em educação.

Por fim, de acordo com a CF de 1988, é direito de todos e dever do Estado, bem como de outras instâncias, garantir a educação, como já citado acima. A LDB, no Capítulo II que trata da Educação Básica, na Seção V, versando sobre a Educação de Jovens e Adultos, juntamente com o Artigo 37 e 38, garante que as pessoas adultas que não tiveram acesso à escola na idade própria, o façam agora, também de forma gratuita, assegurando, ainda, sua permanência.

Vale ressaltar a importância da educação na vida das pessoas, sejam elas crianças, adolescentes e jovens ou adultas. A educação de pessoas jovens e adultas merece destaque, justamente por não terem oportunidade de formação na idade considerada certa ou própria, buscando, mais tarde, esta formação, seja para atualização, para a própria formação ou certificação para o mercado de trabalho. De qualquer forma, a educação é direito de todos e deve ser assegurada pelo Estado; esta deve ser exigida pela população, especialmente a mais desfavorecida, pois é justamente um direito e está previsto em lei. Assim, de modo geral, o Plano Nacional de Educação é uma forma de propor as metas que devem ser seguidas pelo próprio governo; caso sejam cumpridas, isto certamente estará contribuindo para a formação das pessoas; caso não sejam cumpridas, todos devem cobrar mais atenção do governo para que suas políticas sejam efetivadas, especialmente nas bases, na formação inicial das pessoas. Assim, se para fazer um sistema deve haver um Plano Nacional de Educação, tal Plano não pode estar desvinculado com a realidade, pois, ao contrário, fica apenas no papel. Diante do Estado e da reflexão sobre uma Política Pública para melhoria da educação no Brasil, é possível considerar o PIBID como força que dá nova fisionomia e perspectiva educacional, bem como abre portas para fortalecer os estágios nos cursos de licenciatura, dando maiores possibilidades de acesso às escolas parceiras e para nossos licenciandos no que se refere ao olhar a esta realidade com a qual irá relacionar-se em 
breve, atuando, assim, de forma mais consistente, clara e segura, abrindo-se à aprendizagem de forma conjunta.

\section{REFERÊNCIAS}

ADRIÃO, Theresa; CAMARGO, Rubens Barbosa de. A Gestão Democrática na Constituição Federal de 1988. In: MINTO, César Augusto [at al]. Gestão Financiamento e Direito à Educação: Análise da LDB e da Constituição Federal. São Paulo: Xamã, 2001.

GRACINDO, Regina Vinhaes. Gestão democrática nos sistemas e na escola. Brasília: Universidade de Brasília, 2007. Técnico em Gestão Escolar. 72 pág. Disponível em: < http://portal.mec.gov.br/seb/arquivos/pdf/11gesdem.pdf> Acesso em: 30 de julho de 2015.

DAVIES, Nicholas. FUNDEB: A Redenção da Educação Básica? Educação e Sociedade, Campinas, Vol. 27, n 96. Especial, p.753-774. Outubro de 2006.

MURAKANA, Maria Aparecida Segatto; MINTO, César Augusto. Organização da Educação Escolar. In: MINTO, César Augusto [at al]. Gestão Financiamento e Direito à Educação: Analise da LDB e da Constituição Federal. São Paulo: Xamã, 2001.

PINTO, José Marcelino de Rezende. A Política Recente de Fundos para o Financiamento da Educação e seus Efeitos no Pacto Federativo. Educação e Sociedade, Campinas, vol. $28, \mathrm{n}^{\circ} 100$, p.877-897. Outubro de 2007.

VIEIRA, Evaldo. A Política e as Bases do Direito Educacional. Cadernos Cedes, ano XXI, $\mathrm{n}^{\circ}$ 55, Novembro/ 2001. 